\title{
ANALISIS USAHA PERIKANAN TANGKAP CUMI-CUMI PADA NALAYAN TRADISIONAL DI KELURAHAN MOTTO KECAMATAN LEMBEH UTARA KOTA BITUNG
}

\author{
Dian M. Faradizza'; Jardie A. Andaki²; Jeannette F. Pangemanan² \\ 1)Mahasiswa Fakultas Perikanan dan IImu Kelautan Universitas Sam Ratulangi Manado \\ 2)Staff Pengajar Fakultas Perikanan dan IImu Kelautan Universitas Sam Ratulangi Manado \\ Koresponden email: dfaradiiza@gmail.com
}

\begin{abstract}
The purpose of this study was to find out how the characteristics of squid fishermen respondents in Motto Village, North Lembeh Subdistrict, Bitung City and to find out the feasibility of squid fishing business in Motto Village, North Lembeh District, Bitung City. The research method used is a case study. Data collected through 2 sources, namely primary data and secondary data. All data collected in descriptive qualitative and quantitative descriptive based on aspects obtained from the results of observations and interviews by respondents. In analyzing the collected data used descriptive methods that are qualitative in nature, namely analysis obtained from various types of data collection techniques such as interviews by providing descriptions and information using the author's own sentences. Based on the results of the research and discussion it can be concluded: 1) The age range of squid fisherman fishermen respondents ranges from 20-50 years, 100\% religion is Christian, family dependents are 2-5 people, while housing conditions are generally permanent; 2) Squid fishing business in the Motto Village is feasible to run based on financial feasibility criteria.
\end{abstract}

Key Words: Analysis, traditional fishermen, Motto village

\begin{abstract}
Abstrak
Tujuan dari penelitian ini adalah mengetahui bagaimana karakteristik responden nelayan cumi-cumi di Kelurahan Motto, Kecamatan Lembeh Utara, Kota Bitung dan mengetahui bagaimana kelayakan usaha perikanan tangkap cumi-cumi di Kelurahan Motto, Kecamatan Lembeh Utara, Kota Bitung. Metode penelitian yang dipakai adalah studi kasus. Data yang dikumpulkan melalui 2 sumber yaita data primer dan data sekunder. Semua data yang dikumpulkan secara deskriptif kualitatif dan deskriptif kuantitatif berdasarkan aspek yang di peroleh dari hasil observasi dan wawancara oleh responden. Dalam menganalisa data yang telah dikumpulkan digunakan metode deskriptif yang sifatnya kualitatif, yaitu analisis yang diperoleh dari berbagai macam teknik pengumpulan data misalnya wawancara dengan memberikan gambaran serta keterangan dengan menggunakan kalimat penulis sendiri. Berdasarkan hasil penelitian dan pembahasan dapat disimpulkan: 1) Kisaran umur responden nelayan perikanan tangkap cumi-cumi berkisar 20-50 tahun, agama yang dianut 100\% beragama Kristen, tanggungan keluarga berjumlah 2-5 orang, sedangkan kondisi rumah umumnya sudah permanen; 2) Usaha perikanan tangkap cumi-cumi di Kelurahan Motto layák dijalankan berdasarkan kriteria kelayakan finansial.
\end{abstract}

Kata Kunci: Analisis, nelayan tradisional, Kelurahan Motto

\section{PENDAHULUAN}

Sumberdaya alam mempunyai hubungan yang sangat erat dengan pertumbuhan ekonomi yang terjadi di suatu Negara (khususnya Negara sedang berkembang), dimana semakin tinggi pertumbuhan ekonominya, akan mengakibatkan persediaan sumberdaya alam yang tersedia akan semakin berkurang. Hal ini karena pertumbuhan ekonomi yang tinggi akan selalu menuntut adanya barang sumberdaya dalam jumlah yang tinggi pula, dan barang sumberdaya ini diambil dari persediaan sumberdaya alam yang ada. Dengan demikian, terdapat hubungan yang positif antara jumlah barang sumberdaya dengan pertumbuhan ekonomi, di samping juga hubungan yang negative antara persediaan sumberdaya alam dengan pertumbuhan ekonomi (Anhar, 2012). Ikan adalah salah satu sumberdaya alam yang bersifat renewable atau mempunyai sifat dapat pulih/dapat memperbaharui diri.Di samping sifat renewable, menurut Widodo dan Nurhakim (2002), sumberdaya ikan pada umumnya mempunyai sifat "open access" dan "common property" yang artinya pemanfaatan bersifat terbuka oleh siapa saja dan kepemilikannya bersifat umum. 
Sumberdaya perikanan terdiri dari sumberdaya ikan dan non-ikan.Salah satu sumberdaya non-ikan ialah cumicumi.Cumi-cumi termasuk pelagik, tetapi terkadang digolongkan sebagai organism demersal, karena sering berada di dasar, menurut Bakrie(1985)dalam Theresia dkk., (2013). Cumi-cumi melakukan distribusi vertikal pada malam hari, dimana Cumi-cumi bergerak ke arah permukaan untuk mencari makan, sedangkan pada siang hari berada di dasar perairan. Adapun ukuran ekonomis yang sesuai dengan kriteria ramah lingkuangan disesuaikan dengan berat bobot dan panjang tubuh.

Di Indonesia potensi cumi-cumi yang cukup besar, termasuk di Sulawesi Utara.Khususnya di Kota Bitung terdapat nelayan yang menangkap cumi-cumi, yaitu di Kelurahan Motto.Kelurahan Motto terdapat di Pulau Lembeh, tepatnya di Kecamatan Lembeh Utara.Keberadaan nelayan cumi-cumi sudah berlangsung lama karena wilayah perairan memiliki sumberdaya cumi-cumi yang melimpah.

Sebagian besar penduduk
Kelurahan Motto memiliki mata pencaharian sebagai nelayan.Nelayan di Kelurahan Motto sebagian besar merupakan nelayan penangkap cumicumi.Salah satu potensi sumberdaya perikanan di perairan Kelurahan Motto yang bernilai ekonomis penting dan banyak dikonsumsi di Kelurahan Motto ini ialah cumi-cumi. Cumi-cumi merupakan salah satu jenis sumber daya perikanan yang berperan nyata dalam sektor perikanan laut dan banyak dikomsumsi oleh masyarakat, dan merupakan hasil tangkapan yang melimpah di Kelurahan Motto, Kecamatan Lembeh Utara, Kota Bitung.

Perikanan cumi-cumi yang telah berlangsung sejak lama, dilakukan oleh nelayan tradisional.Nelayan tradisional memiliki karakteristik subsisten, dalam arti hanya menangkap untuk kebutuhan sehari-hari dan sebagian kecil untuk dijual.Karakteristik ini menggambarkan nelayan yang bersangkutan kurang atau tidak memiliki perencanaan dalam menjalankan usaha apalagi mengembangkan usaha penangkapan cumi-cumi menjadi lebih baik.Salah satu instrumen yang sering digunakan untuk menggambarkan kinerja suatu usaha ialah analisis usaha, yang di dalamnya juga termasuk analisis finansial,

\section{METODE PENELITIAN}

Metode penelitian ini menggunakan metode studi kasús, studi kasus adalah suatu penelitian kualitatif yang berusaha menemukan makna, menyelidiki proses, memperoleh pengertian dan pemahaman yang mendalam dari individu, kelompok atau situasi (Emzir, 2011), sedangkan menurut Mantjoro (1980) studi kasus adalah penelitian yang dilakukan terfokus pada suatu kasus tertentu untuk diamati dan di analisis secara cermat sampai tuntas.

Dalam penelitian ini data yang digunakan terdiri dari data primer dan data sekunder. Data primer diperoleh langsung dari sumber penelitian melalui beberapa kegiatan, antara lain:

a. Observasi: pengumpulan data melalui pengamatan secara langsung terkait usaha perikanan cumi-cumi di Kelurahan Motto, Kecamatan Lembeh Utara Kota Bitung.

b. Wawancara: pengumpulan data dengan cara kegiatan tanya-jawab langsung dengan para nelayan penangkap cumi-cumi

c. Dokumentasi: data yang diperoleh dalam bentuk tertulis berupa pustaka mengenai Kelurahan Motto. 
d. Kuisioner: data yang diperoleh dengan cara memberikan kuis berupa kertas untuk diisi sesuai dengan kegiatan penangkapan yang terjadi di Kelurahan Motto.

Sedangkan, data sekunder diperoleh secara tidak langsung serta penunjang data primer melalui studi pustaka dan lembaga pemerintahan berupa jumlah penduduk, letak geografis, dan hal-hal lain yang terkait dengan penelitian ini.

Dalam menganalisa data yang telah dikumpulkan digunakan metode deskriptif yang sifatnya kualitatif, yaitu analisis yang diperoleh dari berbagai macam teknik pengumpulan data misalnya wawancara dengan memberikan gambaran serta keterangan dengan menggunakan kalimat penulis sendiri, secara sistematis dan mudah dimengerti sesuai dengan data yang telah diperoleh. Sedangkan untuk metode analisis kuantitatif merupakan analisis data yang berbentuk angka atau bilangan dengan menggunakan perhitungan matematika sederhana, seperti perkalian, pembagian dan persentase.

Menurut Kadirah (1995), untuk mengetahui tingkat kelayakan usaha digunakan analisis finansial dengan menggunakan formula yang terdiri dari :
1) Operating Profit
2) NetProfit $(\pi)$
3) Profit Rate
4) Benefit Cost
5) Rentabilitas
6) Break Event
7) Payback Period

\section{HASIL DAN PEMBAHASAN}

Analisis Usaha Investasi (I) dan Biaya Tetap (FC)

Usaha perikanan tangkap cumicumi membutuhkan investasi guna menjalankan operasi penangkapan.
Investasi dimaksud membutuhkan sumber dana dalam pengadaannya. Identifikasi barang modal sebagai investasi usaha perikanan tangkap cumicumi (Lampiran 2) serta rata-rata investasi tiap responden disajikan pada tabel 1. Demikian pula perhitungan untuk biaya tetap.

Tabel 1. Biaya Investasi dan Biaya Tetap.

\begin{tabular}{|c|c|c|c|}
\hline No. & Resp. & $\begin{array}{l}\text { Investasi } \\
\text { (Rp.) }\end{array}$ & $\begin{array}{c}\text { Biaya Tetap (FC) } \\
\text { (Rp.) }\end{array}$ \\
\hline 1. & R1 & 11.500 .000 & 1.200 .000 \\
\hline 2. & $\mathrm{R} 2$ & 11.400 .000 & 1.200 .000 \\
\hline 3. & R3 & 10.600 .000 & 1.120 .000 \\
\hline 4. & $\mathrm{R} 4$ & 11.200 .000 & 1.160 .000 \\
\hline 5. & R5 & 12.500 .000 & 1.300 .000 \\
\hline 6. & R6 & 11.100 .000 & 1.170 .000 \\
\hline 7. & R7 & 11.800 .000 & 1.230 .000 \\
\hline 8. & R8 & 11.500 .000 & 1.200 .000 \\
\hline 9. & $\mathrm{R} 9$ & 12.800 .000 & 1.360 .000 \\
\hline 10. & R10 & 11.900 .000 & 1.250 .000 \\
\hline \multicolumn{2}{|c|}{ Jumlah } & 116.300 .000 & 12.190 .000 \\
\hline \multicolumn{2}{|c|}{ Rata-rata } & 11.630 .000 & 1.219 .000 \\
\hline
\end{tabular}

Pada tabel 1 yang termasuk biaya investasi ialah biaya pembuatan perahu yang termasuk juga biaya pembelian mesin perahu, pembelian kayu, pembayaran tukang dan pembelian karburator pada perahu dan biaya tetap yang dimaksud ialah biaya penyusutan dari biaya investasi tersebut. Rata-rata biaya investasi yang ada, yaitu Rp. 11.630.000 dan rata-rata biaya tetap dari 10 responden tersebut adalah $\mathrm{Rp}$. 1.219.000.

\section{Biaya Tidak Tetap (VC)}

Pada usaha perikanan tangkap cumi-cumi juga membutuhkan sumber biaya tidak tetap dalam pengadaannya. Identifikasi dana sebagai biaya tidak tetap dari usaha perikanan tangkap cumi-cumi (Lampiran 3) serta rata-rata biaya tidak tetap tiap responden disajikan pada tabel 2. 
Tabel 2. Biaya Tidak Tetap dalam 1 tahun.

\begin{tabular}{|c|c|c|}
\hline No. & Resp. & Biaya Tidak Tetap (Rp.) \\
\hline 1. & R1 & 23.950 .000 \\
\hline 2. & R2 & 24.032 .000 \\
\hline 3. & R3 & 24.838 .000 \\
\hline 4. & R4 & 20.852 .000 \\
\hline 5. & R5 & 24.892 .000 \\
\hline 6. & R6 & 20.684 .000 \\
\hline 7. & R7 & 24.028 .000 \\
\hline 8. & R8 & 24.292 .000 \\
\hline 9. & R9 & 20.504 .000 \\
\hline 10. & R10 & 24.784 .000 \\
\hline & Jumlah & 232.856 .000 \\
\hline & Rata-rata & 23.285 .600 \\
\hline
\end{tabular}

Sumber: Pengolahan data primer (2019)

Pada tabel 2 menunjukkan biaya tidak tetap dalam penangkapan cumicumi diantara biaya yang ada yaitu untuk senar, mata pancing, senter, ember, batre senter, minyak (bahan bakar), rokok dan konsumsi.Jumlah keseluruhan biaya tidak tetap dari 10 responden tersebut adalah $\mathrm{Rp} .232 .856 .000$ dan rata-rata biaya tidak tetapnya adalah Rp. 23.285.600 biaya tidak tetap ini dikalkulasikan dalam 1 tahun.

\section{Pendapatan (TR)}

Pendapatan merupakan indikator penting dari usaha perikanan tangkap ini, dari pendapatan yang di dapat jika bisa melebihi biaya investasi maka usaha ini bisa dikatakan layak untuk dijalankan. Identifikasi dana sebagai pendapatan dari usaha perikanan tangkap cumi-cumi serta rata-rata pendapatan tiap responden disajikan pada tabel 3 .

Tabel 3. Pendapatan Responden Perminggu, perbulan dan pertahun.

\begin{tabular}{|c|c|c|c|c|}
\hline No. & Resp. & $\begin{array}{c}\text { Pendapatan per Minggu } \\
\text { (Rp.) }\end{array}$ & $\begin{array}{c}\text { Per Bulan } \\
\text { (Rp.) }\end{array}$ & $\begin{array}{c}\text { Per Tahun } \\
\text { (Rp.) }\end{array}$ \\
\hline 1. & R1 & 1.500 .000 & 6.000 .000 & 54.000 .000 \\
\hline 2. & R2 & 2.000 .000 & 8.000 .000 & 72.000 .000 \\
\hline 3. & R3 & 1.500 .000 & 6.000 .000 & 54.000 .000 \\
\hline 4. & R4 & 2.000 .000 & 8.000 .000 & 72.000 .000 \\
\hline 5. & R5 & 2.000 .000 & 8.000 .000 & 72.000 .000 \\
\hline 6. & R6 & 1.000 .000 & 4.000 .000 & 36.000 .000 \\
\hline 7. & R7 & 1.000 .000 & 4.000 .000 & 36.000 .000 \\
\hline 8. & R8 & 1.000 .000 & 4.000 .000 & 36.000 .000 \\
\hline 9. & R9 & 3.000 .000 & 9.000 .000 & 81.000 .000 \\
\hline 10. & R10 & 1.500 .000 & 6.000 .000 & 54.000 .000 \\
\hline & Jumlah & 16.900 .000 & 61.600 .000 & 567.000 .000 \\
\hline & Rata-rata & 1.690 .000 & 6.160 .000 & 56.700 .000 \\
\hline
\end{tabular}

Sumber: Pengolahan data primer (2019)

Pada tabel 3 dijelaskan bahwa jumlah pendapatan yang ada dalam seminggu sekitar ${ }^{\circ p}$. 16.900.000 dan rata-rata pendapatan dalam seminggu ialah Rp. 1.690.000, pendapatan perbulan adalah Rp. 61.600 .000 dan rata-rata pendapatan dalam sebulan sekitar Rp. 6.160.000, dan pendapatan dalam 1tahun dari keseluruhan responden adalah Rp. 567.000.000 dan rata-rata pendapatan perorang dalam 1 tahun, adalah Rp. 56.700.000.

\section{Analisis Finansial}

Diketahui:

I : Rp. 11.630 .000

TR : Rp. 56.700 .000

TC : Rp. 24.504 .600

FC : Rp. 1.219 .000

VC : Rp. 23.285.600

\section{Operating Profit}

$$
\begin{aligned}
\mathrm{OP} & =\mathrm{TR}-\mathrm{VC} \\
\mathrm{OP} & =\mathrm{Rp} .56 .700 .000-R p .23 .285 .600 \\
& =\text { Rp. } 33.414 .400
\end{aligned}
$$

Pada Operating Profit dijelaskan pada rumus di atas bahwa jika Total Revenue atau pendapatan Rp. $\quad 56.700 .000$ dikurangi dengan biaya tidak tetap (Variable Cost) Rp. 23.285.600 hasilnya kelangsungan usaha yang telah 
dijalankan telah didapat Rp. 33.414 .400 untuk biaya oprasionalnya.

\section{Net Profit ( $\pi)$}

$\pi=\mathrm{TR}-\mathrm{TC}$

Ket :

$\mathrm{TR}=$ Total penerimaan

$\mathrm{TC}=$ Total biaya

Net profit $=$ Rp. $56.700 .000-$ Rp. $24 \cdot 504 \cdot 600=$ Rp. 32.195 .400

Net Profit atau dapat kita sebut sebagai keuntungan telah dijelaskan dari rumus di atas bahwa jika Pendapatan (TR) Rp. Rp. 56.700.000 dikurangi Biaya Total (TC) Rp. 24.504.600 dari usaha yang telah dijalankan ini adalah $\mathrm{Rp}$. 32.195.400. Keuntungan yang didapat disini cukup besar pertahunnya, dan ini dapat disimpulkan bahwa usaha ini sangat layak untuk dijalankan.

3. Profit Rate

$$
\begin{aligned}
& \text { Profit rate }=\frac{\pi}{T C} \times 100 \% \\
& \text { Ket : } \\
& \pi=\text { Total Profit } \\
& \mathrm{TC}=\text { Total biaya } \\
& \text { Profit rate }(P R) \quad=\frac{\text { Rp. } 32.195 .400}{\text { Rp. } 24.504 .600} \times 100 \% \\
& P R \quad=1.31
\end{aligned}
$$

Pada Profit Rate menunjukkan persentase yang didapat adalah 1,31 .

\section{Benefit cost Ratio}

$$
\begin{aligned}
& \mathrm{BCR}=\mathrm{TR} / \mathrm{TC} \\
& \mathrm{Ket}: \\
& \mathrm{TR}=\text { Total penerimaan } \\
& \mathrm{TC}=\text { Total biaya } \\
& \mathrm{BCR}=\frac{\mathbf{R p} .56 .700 .000}{\mathbf{R p} .24 .504 .600}=2.31
\end{aligned}
$$

Benefit cost ratio adalah perkiraan manfaat yang diharapkan pada waktu mendatang atau rasio penerimaan dengan seluruh pengeluaran dan BCR yang didapat adalah 2,31 jika diartikan dalam penilaian BCR ini > 1 yang berarti usaha ini layak untuk dijalankan dan menguntungkan.

$$
\begin{aligned}
& \text { 5. Rentabilitas } \\
& \frac{\pi}{I} \times \mathbf{1 0 0 K e t} \\
& \text { Ket : } \\
& \pi=\text { Total profit } \\
& \text { I = investasi }
\end{aligned}
$$

Rentabilitas $=\frac{\text { Rp.32.195.400 }}{R p \cdot 11.630 .000} \times 100 \%$
$=276$

Emawati (2007) menyatakan bahwa ada lima kriteria rentabilitas, yaitu :

- Rentabilitas 1 - 25,5\% kategori buruk

- Rentabilitas 26 - 50\% kategori rendah

- Rentabilitas 51 - 75\% kategori cukup

- Rentabilitas 76 - 100\% kategori baik

- Rentabilitas > 100\% kategori baik sekali

Rentabilitas merupakan ratio tingkat keuntungan bersih dengan investasi dalam satu unit usaha dengan jumlah yang didapat adalah 276, dalam kriteria Rentabilitas yang didapat melebihi $100 \%$ berarti usaha yang dijalankan sangat baik sekali untuk diteruskan.

\section{Break Even Point (BEP)}

a) BEP Penjualan $=\frac{F C}{1-\frac{V C}{T R}}$

b) BEP Satuan = BEP Penjualan $/$ Harga satuan

Ket :

$\mathrm{FC}=$ Biaya tetap

$\mathrm{VC}=$ Biaya tidak tetap

$\mathrm{TR}=$ Total penerimaan

Jawaban:

$$
\begin{aligned}
\text { a) BEP penjualan }=\frac{\text { Rp.1.219.000 }}{1-\frac{R p \cdot 23.285 .600}{\text { Rp.56.700.000 }}} \\
=\frac{\text { Rp.1.219.000 }}{\mathbf{1}-0.41} \\
=\frac{\text { Rp.1.219.000 }}{0.58} \\
=\text { Rp. } 2.101 .724 \\
\text { b) BEP satuan }=\text { Rp. } 2.101 .724: \text { Rp. } \\
17.000 / \mathrm{kg}=123 \mathrm{~kg}
\end{aligned}
$$

BEP merupakan suatu nilai dimana hasil penjualan produksi sama dengan biaya produksi sehingga pengeluaran sama dengan pendapatan. BEP Penjualan yang didapat adalah Rp. 2.101.724 dengan satuan yang didapat adalah 123 $\mathrm{kg}$. Nilai ini menggambarkan batas dimana produksi nelayan cumi-cumi lebih dari $123 \mathrm{~kg}$ maka akan mendapatkan keuntungan demikian sebaliknya jika produksi kurang dari 123 $\mathrm{kg}$ maka akan mengalami kerugian. 
Demikian dengan nilai penjualan di atas Rp. 2.101.724 maka nelayan akan mendapatkan keuntungan dan sebaliknya jika penjualan di bawah Rp. 2.101.724 maka akan mengalami kerugian.

\section{Payback Period (PP)}

Payback Period $=\frac{I}{\pi} \times 1$ tahun

Ket :

I = Investasi

$\pi=$ Total profit

$\mathrm{PP}=\frac{R p .11 .630 .000}{\mathrm{Rp} .32 .195 .400} \times 12$ bulan $=4.33$ bulan (4 bulan 10 hari)

Payback Periodatau jangka waktu pengembalian yang dibutuhkan untuk menutup kembali biaya investasi usaha dengan aliran kas yang ada adalah 4,33 bulan (4 bulan 10 hari), saat itu juga usaha dapat dibilang bisa mengembalikan modal yang pernah dikeluarkan.

\section{KESIMPULAN}

Berdasarkan hasil penelitian dan pembahasan dapat disimpulkan kisaran umur responden nelayan perikanan tangkap cumi-cumi berkisar 20-50 tahun, agama yang dianut $100 \%$ beragama Kristen, tanggungan keluarga berjumlah 2-5 orang, dan kondisi rumah umumnya sudah permanen.

Usaha perikanan tangkap cumicumi di Kelurahan Motto layak dijalankan berdasarkan kriteria kelayakan finansial.

\section{DAFTAR PUSTAKA}

Andaki, J.A., 2003. Analisis Komparatif Agribisnis Peternakan Rakyat Ayam Ras Pedaging Sistem Mandiri dan Sistem Kemitraan di Kabupaten Minahasa. Tesis. Managemen Agribisnis. Program Pascasarjana UNSRAT. Manado.
Andaki, J.A., 2012. Masyarakat Pantai Kota Manado Pasca Reklamasi. Disertasi.Program Pascasarjana Universitas Padjadjaran Bandung.

Anggraini, S., 2008. Analisis Kelayakan Finansial Usaha Ikan Mas dengan Cara Pemberokan. Institut Pertanian Bogor.

Anonimous, 1989. Kamus Besar Bahasa Indonesia. Departemen Pendidikan dan Kebudayaan. Balai Pustaka Jakarta.

Beattie, B.R., dan C.R. Taylor, 1994. Ekonomi Produksi. Gadjah Mada University Press, Yogyakarta.

Departemen Kelautan dan Perikanan R.I., 2002.Keputusan Mentri Kelautan dan Perikanan No.Kep.10/Men/2002 tentang Pedoman Umum Perencanaan Pengelolaan Pesisir Terpadu.

Emzir.2011. Metodologi Penelitian Kualitatif Analisis Data. Rajawali Pers. Jakarta

Gittinger, J.R. 1986. Analisa Ekonomi ProyekProyek Pertanian. Universitas Indonesia (UIPress), Jakarta.

Herjanto, 2007. Manajemen Operasi Edisi ketiga. Grasindo. Jakarta

Husnan, S., Muhammad, S. 2000. Studi Kelayakan Proyek. Yogyakarta.

Imron, M., 2003. Kemiskinan Dalam Masyarakat Nelayan. Jurnal Masyarakat dan Budaya. Jakarta: PMB-LIPI.

Kadirah. 1995. Evaluasi Proyek Analisa Ekonomi. Edisi Kedua. Universitas Indonesia Jakarta.

Lukman, 2004. Manajemen Keuangan. Penerbit Raja Grafindo Persada. Jakarta

Mantjoro, E. 1980. Metodologi Penelitian. Pengantar Kuliah Metodelogi Penelitian. FPIK UNSRAT. Manado

Mulyadi, 1993. Akuntansi Biaya, Penentuan Harga Pokok dan Pengendalian Biaya. BPFE, Yogyakarta.

Prabawa, S. 1998. Sumberdaya Keluarga dan Tingkat Kesejahteraan Rumahtangga Petani, Studi Desa Water Jaya, Kecamatan Cijeruk. Kabupaten Bogor, Jawa Barat [Tesis]. Bogor : Program Pascasarjana, Institut Pertanian. Bogor.

Rahardi dan Hartanto. 2003. Agribisnis Peternakan. Penebar Swadaya. Jakarta. 